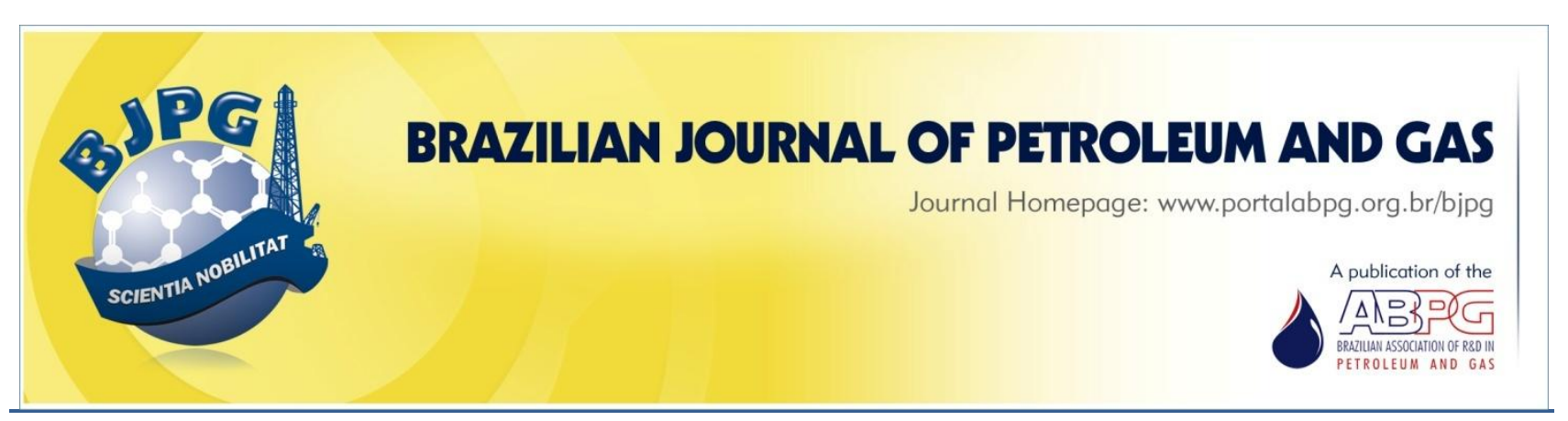

\title{
ANALYSIS OF DIFFERENT OIL-WELL CONFIGURATIONS IN THE SAGD PROCESS CONSIDERING PRESSURE DROP AND HEAT LOSS IN THE INJECTION WELL
}

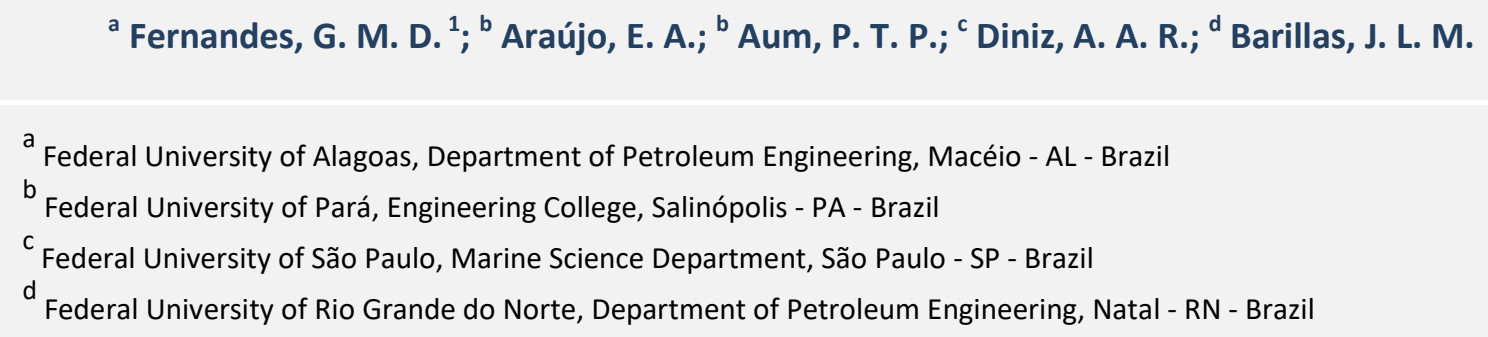

Received: 27.03.2019 / Revised: 16.04.2019 / Accepted: 08.05.2019 / Published on line: 18.06.2019

\begin{abstract}
Many of Brazilian heavy oil reserves are located in the Northeast geographic region of Brazil. Presently, those reserves are being recovered using thermal recovery methods. To investigate the opportunity of improving the performance of configurations based on the SAGD process in fields with the characteristics of the Brazilian Northeast, a numerical simulation study was conducted in a semisynthetic reservoir, reproducing those characteristics. A W-SAGD configuration, with two parallel injector wells, in a different vertical alignment was proposed. Results revealed that keeping a steam injection of 200 ton/day anticipated the W-SAGD-25 oil production, improving recovery efficiency.
\end{abstract}

\section{KEYWORDS}

SAGD; heavy oil; numerical simulation; pressure drop

\footnotetext{
${ }^{1}$ To whom all correspondence should be addressed. Address: Federal University of Alagoas, A. C. Simões Campus, Technology Center, Petroleum Engineering Department, Lourival Melo Mota Ave., s/n, Tabuleiro do Martins, Maceió, Alagoas, Brazil. ZIP Code: 57072-900 | e-mail: glydianne.fernandes@ctec.ufal.br doi:10.5419/bjpg2019-0010
} 


\section{INTRODUCTION}

As the world's demand for oil is growing continuously and conventional sources have been widely produced (Araújo et al. 2016), the oil industry is increasing its focus on recovering nonconventional hydrocarbons. About $70 \%$ of the world's companies are looking for hydrocarbon sources involving heavy oil, extra-heavy oil, and bitumen. It is also known that $90 \%$ of these kinds of accumulations are located in Venezuela and Canada (Rojas et al., 2010).

In this context, Rio Grande do Norte stands out among Brazilian states located in the Northeast region, because it has had a long tradition of producing heavy oil through onshore wells, resulting in a large number of mature fields. This also makes the state a strong candidate for the application of techniques that seek to improve oil recovery (Araújo et al., 2016). The exploitation of these resources has been demanded over time due to the overwhelming necessity for new sources of hydrocarbons. Currently, the Northeast area of the Brazilian territory has numerous heavy oil reserves that use thermal recovery methods to increase production.

Figure 1 shows the Steam Assisted Gravity Drainage (SAGD) with two parallel horizontal wells, which is a concept developed by Roger Butler, in 1978 (Butler, 1991). This thermal method uses steam injection and horizontal wells in its configuration to promote the recovery of heavy oil and bitumen. Most of the configurations implemented involve the use of two parallel horizontal wells, one above the other, with a vertical separation distance of 5 meters between them. The well located above is configured as the steam injector, and the well located below as the hydrocarbon producer (Thorne \& Zhao, 2009). When steam is injected continuously, the oil is heated and forms a steam-growing chamber, upwards and sideways, to find the boundaries of the reservoir (Butler, 1991). In a thin oil reservoir, the growth of the steam chamber first finds a vertical limitation. When it reaches the top of the reservoir, from this point onward, it continues its growth up, reaching its lateral limits.

The use of horizontal wells, in SAGD, in comparison to the use of vertical wells, allows a large contact area to be reached within the reservoir. The increased productivity makes drilling of horizontal wells economically attractive (Terez \& Ehlig-Economides, 2002). For projects that use steam injection, well productivity and drained area suffer a limitation, when considering the effects of pressure drop and heat through the injection well. Pressure drop can result in wells with a nonuniform distribution of steam. Thus, a non-uniform steam chamber is formed, reducing the effective length and well productivity (Thorne \& Zhao 2009). Most modelings disregard these two effects (pressure drop and heat loss); however, they should be considered, as they influence the efficiency of the method.

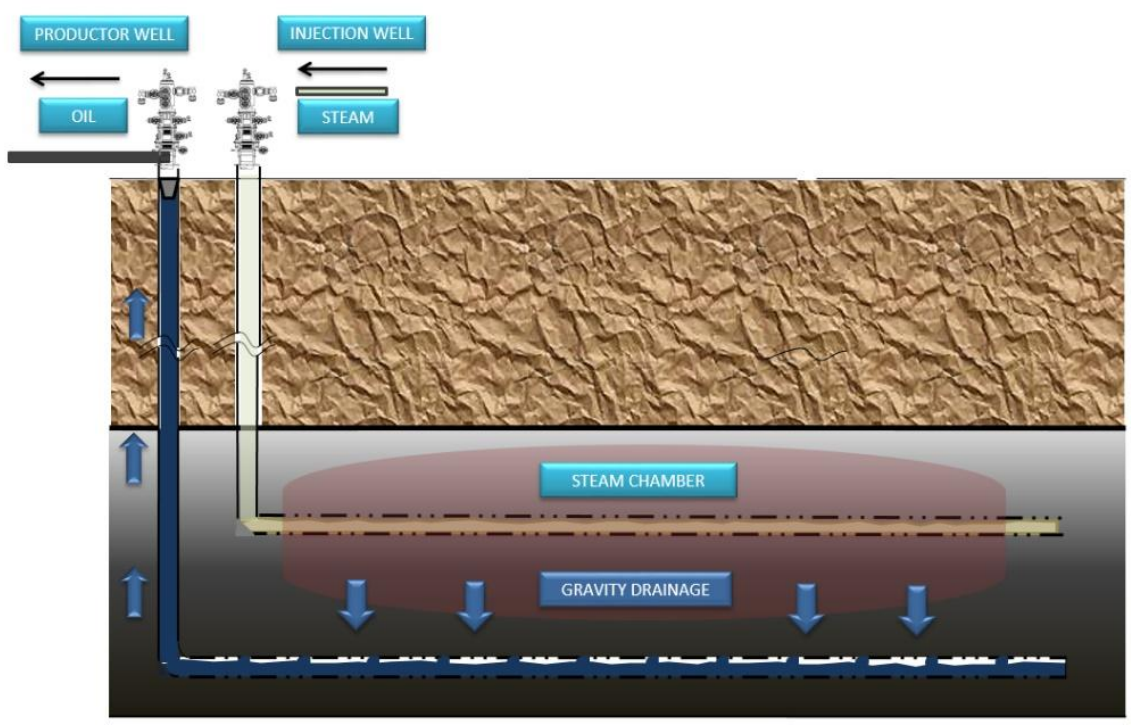

Figure 1. Illustration of the SAGD process. 


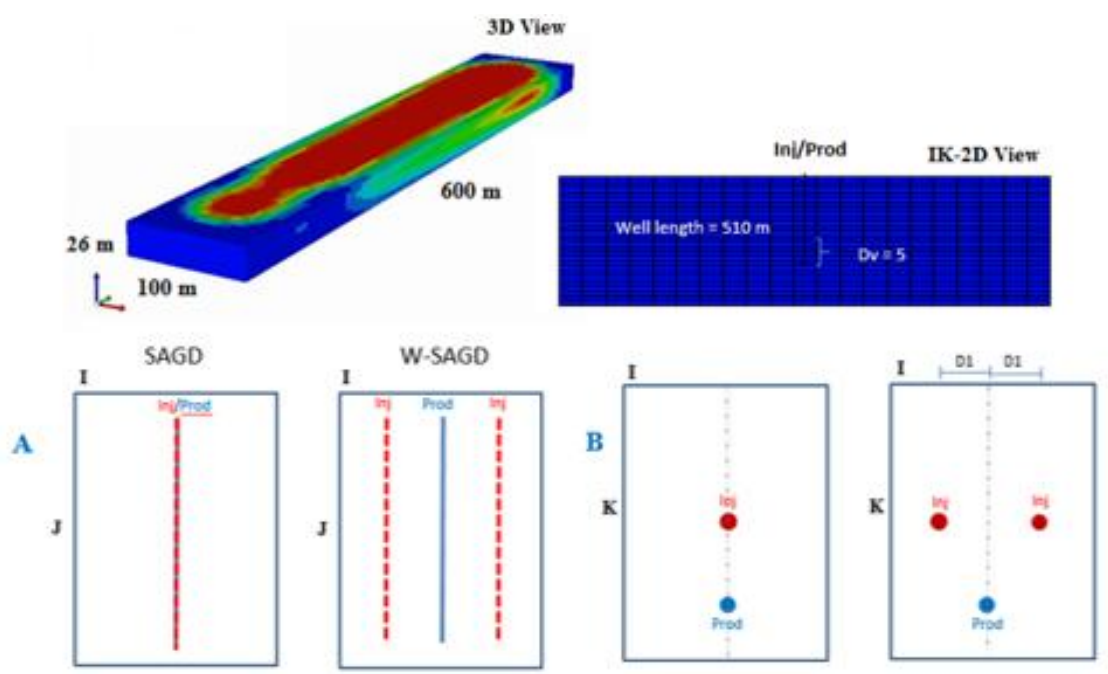

Figure 2. 2D and 3D views of the reservoir for different configurations.

To obtain a better understanding of the performance of the SAGD process in fields with the characteristics of the Brazilian Northeast region, we conducted a numerical simulation study. The purpose of this article is to analyze different well positioning of steam injection wells based on the SAGD configuration. The goal is to optimize oil recovery in models with pressure drop and heat loss. These new well configurations are different from the standard SAGD because they consider an offset of the injector well. In some configurations, for example, the injector is not exactly above the producer well, not affecting its operating principle based on drilling horizontal wells and the action of gravitational forces.

To reach this goal, we considered a semisynthetic reservoir, with characteristics similar to those found in the Brazilian Northeast region. All results were obtained by using a commercial thermal simulator named STARS (Steam, Thermal, and Advanced Processes Reservoir Simulator), by the CMG (Computer Modelling Group Ltd.).

\section{METHODOLOGY}

A homogeneous reservoir, distributed over an area of $100 \mathrm{~m} \times 600 \mathrm{~m}$, with thickness of $26 \mathrm{~m}$, was modeled. Figure 2 shows 2D and 3D views of the numerical model for the analyzed configurations.

Table 1 shows reservoir properties, similar to those found in the Brazilian Northeast (Fernandes

Table 1 Reservoir Properties.

\begin{tabular}{cc}
\hline Property & Value \\
\hline Total grid blocks & 40,950 \\
Reservoir size in x-direction $(\mathrm{m})$ & 100 \\
Reservoir size in y-direction $(\mathrm{m})$ & 600 \\
Reservoir size in z-direction $(\mathrm{m})$ & 26 \\
Initial reservoir temperature $\left({ }^{\circ} \mathrm{C}\right)$ & 37.8 \\
Porosity (\%) & 30 \\
Horizontal permeability (mD) & 1,000 \\
Vertical permeability (mD) & 100 \\
Water-oil contact (m) & 220 \\
Original oil in place ( $\left.{ }^{3} \mathrm{SC}\right)$ & 194,649 \\
Steam quality & 0.5 \\
Reservoir top $(\mathrm{m})$ & 200 \\
Initial pressure (psia) at the top of reservoir & 289 \\
Initial temperature $\left({ }^{\circ} \mathrm{C}\right)$ & $38\left(100.4{ }^{\circ} \mathrm{F}\right)$ \\
Oil viscosity $(\mathrm{cP})$ & 714 \\
Connate water saturation, Sw $(\%)$ & 39 \\
\hline
\end{tabular}


Table 2 Oil composition.

\begin{tabular}{cc}
\hline Component & Initial molar fraction \\
\hline $\mathrm{CO}_{2}-\mathrm{N}_{2}$ & 0.0072 \\
$\mathrm{C}_{1}-\mathrm{C}_{3}$ & 0.1035 \\
$\mathrm{IC}_{4}-\mathrm{C}_{6}$ & 0.0037 \\
$\mathrm{C}_{7}-\mathrm{C}_{20}$ & 0.2059 \\
$\mathrm{C}_{21}-\mathrm{C}_{39}$ & 0.4255 \\
$\mathrm{C}_{40+}$ & 0.2542 \\
\hline
\end{tabular}

Table 3 Well operating parameters.

\begin{tabular}{cc}
\hline Operating parameters & Values \\
\hline Maximum bottom hole pressure for the injector well $(\mathrm{kPa})$ & $7,198.1$ \\
Minimum bottom hole pressure for the productor well $(\mathrm{kPa})$ & 196.5 \\
Steam temperature $\left({ }^{\circ} \mathrm{C}\right)$ & 287.7 \\
Steam rate (ton $/$ day) & 200 \\
Maximum liquid rate in producer well $\left(\mathrm{m}^{3} \mathrm{SC} /\right.$ day) & 1,500 \\
Project time (years) & 20 \\
\hline
\end{tabular}

et al., 2017). Simulations were performed considering the system without an active aquifer. For the numerical simulations, we used the STARS simulator, from the Computer Modeling Group Ltd., which is a multi-component three-phase software that allows the simulation of thermal methods.

Table 2 shows reservoir's oil composition. The model, with pseudo-components, was adjusted through the Phase Property Program (WINPROP) module of the CMG Suite. The modeling of pressure drop and heat loss, through the injector well, was performed by using the discretized model of the STARS simulator. This model is more appropriate because it considers the impact of the pressure drop within the injector well and the distribution of the steam in the producer well, where each section of the well is considered as a block attached to the reservoir. The fluid flow equations, for each component of the well, and the energy equations are solved for each block represented within the reservoir.

Table 3 shows the operational parameters defined for the simulated models. For this study, different configurations of wells, with different distances between injector and producer wells were analyzed.

The distances between the injector wells and the nomenclature applied for each configuration are shown in Table 4. SAGD represents the standard configuration, with 0 meters offset in the "ith" layer of the reservoir.

Table 4 Configurations for the W-SAGD wells.

\begin{tabular}{cc}
\hline Configuration & Separation distance $(\mathrm{m})$ \\
\hline SAGD & 0 \\
W-SAGD-7 & 7 \\
W-SAGD-15 & 15 \\
W-SAGD-25 & 25 \\
W-SAGD-37 & 37 \\
W-SAGD-50 & 50 \\
\hline
\end{tabular}




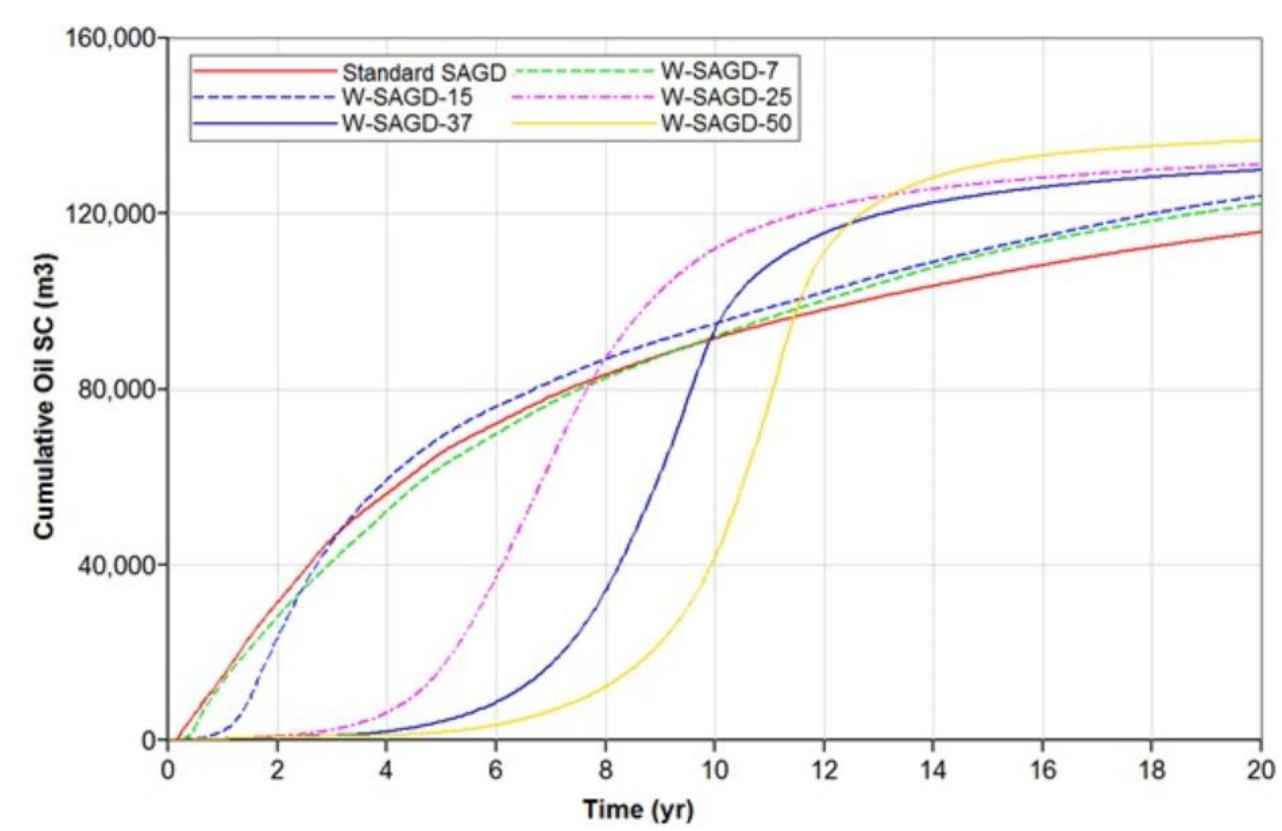

Figure 3. Cumulative oil production for different well configurations, with a 200 ton/day steam injection rate.

\section{RESULTS E DISCUSSIONS}

The proposed W-SAGD configuration has the vertical well in a different vertical alignment, seeking to increase productivity. Therefore, in a mesh with multiple pairs of wells, two injector wells, from different pairs, can influence the same producer well.

Figure 3 shows the graph of cumulative oil production for the different distances between the steam injection wells, considering a steam injection rate of 200 ton/day. The study shows that WSAGD-15 and W-SAGD-25 configurations presented greater anticipation of oil production, in relation to the longer distances defined for W-SAGD-W-37 and W-SAGD-50 configurations. However, at the end of the project time, all the configurations presented a similar cumulative production. In a steam injection project, the process costs can be analyzed according to the technical-economic analysis of the relationship between anticipation of production and cumulative oil production. Thus, the use of a configuration with the injector wells close to the production well, in the " $\mathrm{i}$ "t" layer - at a distance of $15 \mathrm{~m}$ to $25 \mathrm{~m}$ - may represent a viable alternative to increase the production of the project.

The configuration with the shortest distance between the wells, N-SAGD-7, showed a cumulative production that was similar to the standard SAGD, considering that the short proximity between the wells is close to the conventional SAGD itself. In this case, the use of injector wells near each other was not effective.

Figure 4 shows the comparison of the temperature map along the reservoir for the standard SAGD configuration. The wells are exactly one above the other and the configuration with the distance of 25 meters (W-SAGD-25) between injector wells, which presented an anticipation in production and a cumulative oil production similar to the configurations with longer separation distances for the steam injection rate of 200 ton/day. With the approximation of the two injector wells and their respective steam chambers, the combined chamber reaches a larger area of the reservoir, providing a better sweep and contact of the steam with the heavy oil, and, hence, it reduces oil viscosity and increases recovery.

After the tenth year of production, configuration W-SAGD-25 showed a greater steam chamber along the reservoir as a result of the junction of the chambers of the two injection wells. Thus, a larger amount of oil is heated and drained towards the producer well located below.

The main factor in the determination of a successful recovery by gravity drainage is the formation of a uniform steam chamber, with greater reach along the reservoir so that more oil is heated and better drained. Therefore, the W-SAGD configuration represents an alternative to be used in heavy oil fields. 

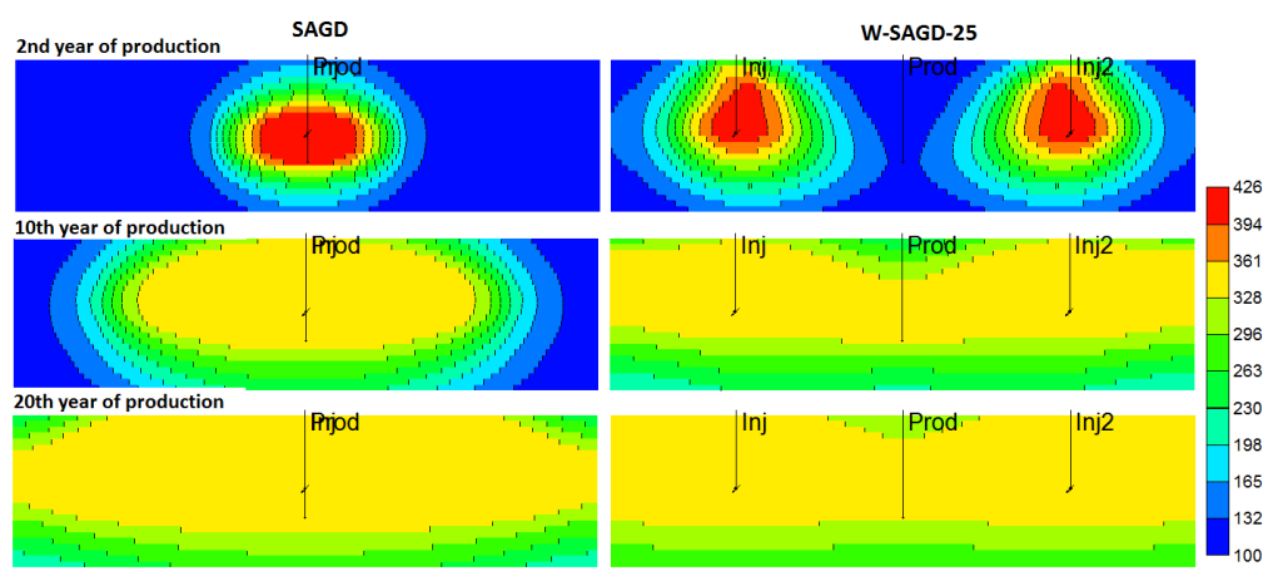

Figure 4. Comparison of temperature distribution for conventional SAGD process and W-SAGD-25 (Qinj = 200 ton/day).

As steam injection projects have a high cost, the increase in production can make the implementation of new SAGD well configurations an alternative to improve the efficiency of the process.

\section{CONCLUSIONS}

The study shows that the W-SAGD-25 configuration, with a separation of 25 meters between injection wells, presented greater anticipation of the cumulative oil production from the eighth to the twelfth year of production onward, when the injection flow rate was 200 ton/day.

The main factor in the determination of a successful oil recovery by gravity drainage is the formation of a uniform steam chamber, with greater reach along the reservoir. The investigation of the W-SAGD configuration represents an alternative to recover heavy oil in Brazilian Northeast, but future studies should investigate the viability of new configurations considering the costs associated with the process.

\section{ACKNOWLEDGMENTS}

Edson A. Araújo and Pedro T. P. Aum acknowledge the financial support provided by Prodoutor/Propesp/UFPA and Foundation for Research Support of the State of Pará (Fapespa Fundação Amazônia de Amparo a Estudos e Pesquisas).

\section{CONFLICT OF INTEREST}

The authors declare no conflict of interests.

\section{REFERENCES}

Araújo, E. A.; Diniz, A. A. R.; Gurgel, A. R.; Lima, D. M. S.; Dutra Jr, T. V.; Barillas, J. L. M. Analysis of oil production by applying in situ combustion, Petroleum Science and Technology, v. 34, n.1, p. 51-55, 2016.

https://doi.org/10.1080/10916466.2015.1098664

Butler, R. M. Thermal recovery of oil and bitumen. V. 7. New Jersey (USA): Prentice Hall, p. 285-358, 1991.

Fernandes, G. M. D.; Diniz, A. A. R.; Araújo, E. A.; Rodrigues, M. A. F.; Gurgel, A. R.; Dutra Jr, T. V.; Barillas, J. L. M. Economic analysis of oil production by applying steam-assisted gravity drainage (SAGD) to reservoir from the Potiguar basin. Economic Sources, Part B: Economics, Planning, and Policy, p. 1-6, 2017.

https://doi.org/10.1080/15567249.2016.1164766

Rojas, J. A.; Ruiz, J.; Vargas, J. Numerical simulation of an EOR process of toe to heel air injection (THAI) - Finding the best well pattern. SPE-129215-MS. SPE EOR Conference at Oil \& Gas West Asis, Muscat, Oman, 11-13 April, 2010. https://doi.org/10.2118/129215-MS 
Terez, I. E.; Ehling-Economides, C. Horizontal wells in thermal applications for displacement and gravity drainage. SPE-78974-MS. SPE International Thermal Operations and Heavy Oil Symposium and International Well Technology Conference, Calgary, Alberta, Canada, 4-7November, 2002. https://doi.org/10.2118/78974-MS
Thorne, T.; Zhao, L. The impact of pressure drop on SAGD process performance. Journal of Canadian Petroleum, v. 48(9), p. 41-46, PETSOC09-09-41, 2009. https://doi.org/10.2118/09-09-41 